\title{
On the imperfection sensitivity and design of spherical domes under external pressure
}

\author{
H.N.R. Wagner ${ }^{\mathrm{a}, *}$, C. Hühne ${ }^{\mathrm{a}, \mathrm{b}}$, J. Zhang ${ }^{\mathrm{c}}$, W. Tang ${ }^{\mathrm{c}}$ \\ ${ }^{a}$ Institute of Adaptronic and Functional Integration, Langer Kamp 6, 38106, Braunschweig, Germany \\ ${ }^{\mathrm{b}}$ Institute for Composite Structures and Adaptive Systems, German Aerospace Center (DLR), Lilienthalplatz 7, 38108, Braunschweig, Germany \\ c School of Mechanical Engineering, Jiangsu University of Science and Technology, Zhenjiang, 212003, China
}

\section{A R T I C L E I N F O}

\section{Keywords:}

Buckling

Robust design

Knockdown factor

Imperfection sensitivity

Spherical shell

\begin{abstract}
A B S T R A C T
Deep spherical shells are often used as pressure vessels in ocean and aerospace engineering. When subjected to external pressure, these thin-walled shells are prone to buckling. The corresponding critical buckling pressure heavily depends on deviations from the ideal shell shape.

In general, these deviations are defined as geometric imperfections, and although imperfections exhibit comparatively low amplitudes, they can significantly reduce the critical load. Considering the influence of geometric imperfections adequately into the design process of thin-walled shells poses major challenges for structural design.

The most common procedure to take into account the influence of imperfections is based on the classical buckling pressure obtained by a linear analysis which are then corrected by a knockdown factor. The knockdown factor represents a statistical lower-bound with respect to data obtained experimentally for different types of thin-walled shells.

This article presents a versatile and simple numerical design approach for deep spherical shells under external pressure. The new design procedure leads to significantly improved critical load estimations in comparison to lower-bounds obtained empirically. Different design example are given and validated with experimental results.
\end{abstract}

in order to determine the reference buckling pressure of underwater pressure hulls like deep sea submersibles [3], underground pressure vessels and tanks [4]. Further applications for spherical shell like structures are lattice domes [5], actuators [6], carbon nanospheres [7], nanocomposite spherical caps [8], biopolymer spherical shells [9], plexiglass shields [10], underwater robots [11] and concave bottom closures of elevated shell-of-revolution liquid-containment tanks [12].

In general, spherical shells are classified as either complete, deep or shallow and the following equation (3) according to Eggwertz et al. [13] can be used to determine if a spherical cap is shallow $(\beta<7)$ or deep $(\beta \geq$ 7):

$\beta=\sqrt{2 \cdot \varphi \cdot\left(\frac{R}{t}\right)}$

Equation (3) depends on the radius $\mathrm{R}$ to thickness $\mathrm{t}$ ratio and the central angle $\varphi$ in radians.

Spherical shells buckle with a sudden drop in pressure and are highly imperfection sensitive [14,15]. The buckling behavior of these shells is

Both equations are widely used in ocean and aerospace engineering

\footnotetext{
* Corresponding author.

E-mail addresses: ro.wagner@tu-braunschweig.de (H.N.R. Wagner), christian.huehne@dlr.de (C. Hühne), tangwenxian@163.com (W. Tang).
} 


\begin{tabular}{|ll|}
\hline Abbreviations and glossary \\
CR & Cutout radius \\
EBC & Energy barrier criterion \\
Exp. & Experiment \\
GNA & Geometrically nonlinear analysis \\
GNIA & Geometrically nonlinear analysis with imperfections \\
H & Dome height \\
KDF & Knockdown factor \\
LBA & Linear bifurcation analysis \\
$\mathrm{P}_{\text {per }}$ & Buckling pressure of perfect spherical shell \\
R & Radius of spherical shells \\
r & Base radius \\
LRSM & Localized Reduced Stiffness Method \\
t & Wall thickness of a spherical shell \\
\hline
\end{tabular}

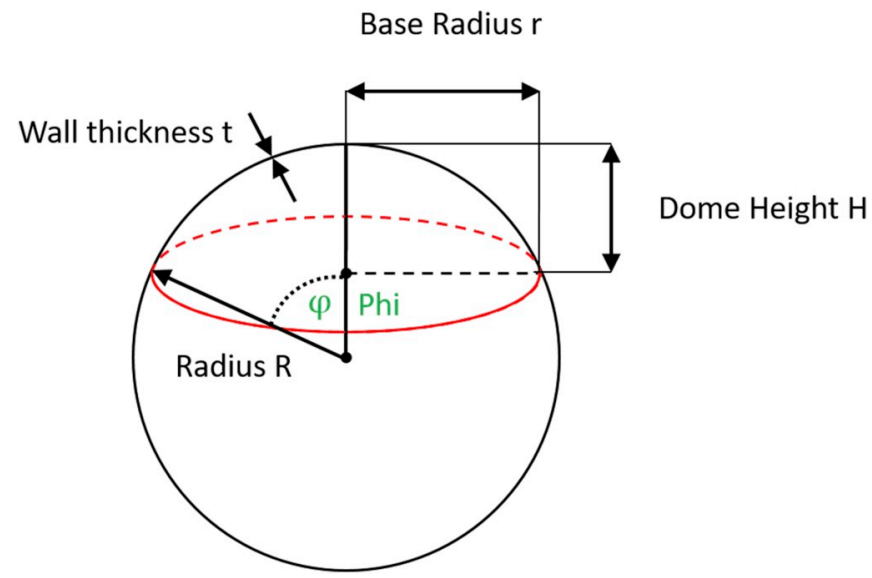

Fig. 1. Geometry of a spherical shell with corresponding parameters.

highly nonlinear [16,17] and multiple different test campaigns [18,19] were performed to study this collapse problem which may have catastrophic consequences.

There is a collection of experimental data for isotropic spherical shells under external pressure summarized from different sources in Fig. 2. The experimental buckling pressure values are represented by means of a knockdown factor (KDF) which is defined as the ratio of the buckling pressure Pexp of a real experimental test shell to the theoretical buckling pressure Pper of a perfect shell, see equation (4). Within this article, the analytical buckling pressure Pper according to equation (1) is used as a reference value for all KDFs.
$K D F_{\text {exp }}=\frac{P_{\text {exp }}}{P_{\text {per }}}$

These KDFs are plotted against the shell shape parameter $\lambda$ which is defined according to equation (5).

$\lambda=\sqrt[4]{\left[12 \cdot\left(1-\nu^{2}\right)\right]} \cdot \sqrt{\frac{R}{t}} \cdot 2 \cdot \sin \left(\frac{\varphi}{2}\right)$

The results show that the experimental buckling pressures can be as low as $20 \%$ of the pressure of a perfect shell. Some of the illustrated tests are affected by plasticity, weld land failure, material failure, and poor boundary support [20]. In addition, most of the test data are poorly documented [21].

Note, that modern experimental campaigns are much better documented [22] as shown by Zhang et al. for egg shaped shells [23-25] complete spherical shells in Refs. [26-29], bi-segment spheres in Ref. [30] and hemi-spheres [31,32].

Karman and Tsien [33] were among the first to investigate the catastrophic nature and the imperfection sensitivity of spherical shells under external pressure. First approaches to explain the significant differences between experimental and theoretical results are based on the energy in the post-buckling state $[34,35]$ or the presence of geometric imperfections [36].

Geometric imperfections are defined as shape deviations from the ideal structure and have been identified by Koiter [37] as one of the main causes for low buckling loads of thin-walled shells like spheres, cylinders [38-43] and cones [44,45].

Depending on the shape and amplitude of the present geometric imperfections a single dimple [46] occurs under loading which initiates the buckling process which was shown by Berke and Carlson [35,47]. The influence of geometric imperfections on the buckling load has to be considered in the design process [48,49]. However, the process of implementing realistic geometric imperfections into the design process is expensive and time consuming.

Therefore, the design of spherical shells relies on the application of empirical knockdown factors [50]. There are design criteria like the NASA SP-8032 [51] which represents a statistical lower bound of different empirical data from the beginning of the 20th century.

A review by Singer et al. [52] shows that the NASA SP-8032 recommendation is a very conservative estimation of the buckling pressure of spherical shells. Therefore, research efforts were focused on developing less conservative design factors for spherical shells under external pressure [53]. Recently, Evkin et al. [54] presented some new design KDF for low [55] and high [56] manufacturing quality spherical shells, composite spherical shells [57] as well as design KDF for the case of dynamic perturbations in spherical shell buckling [58].

This article covers the imperfection sensitivity and design of spherical domes under external pressure. In the second section of this article a numerical model and experimental results of a deep sphere are
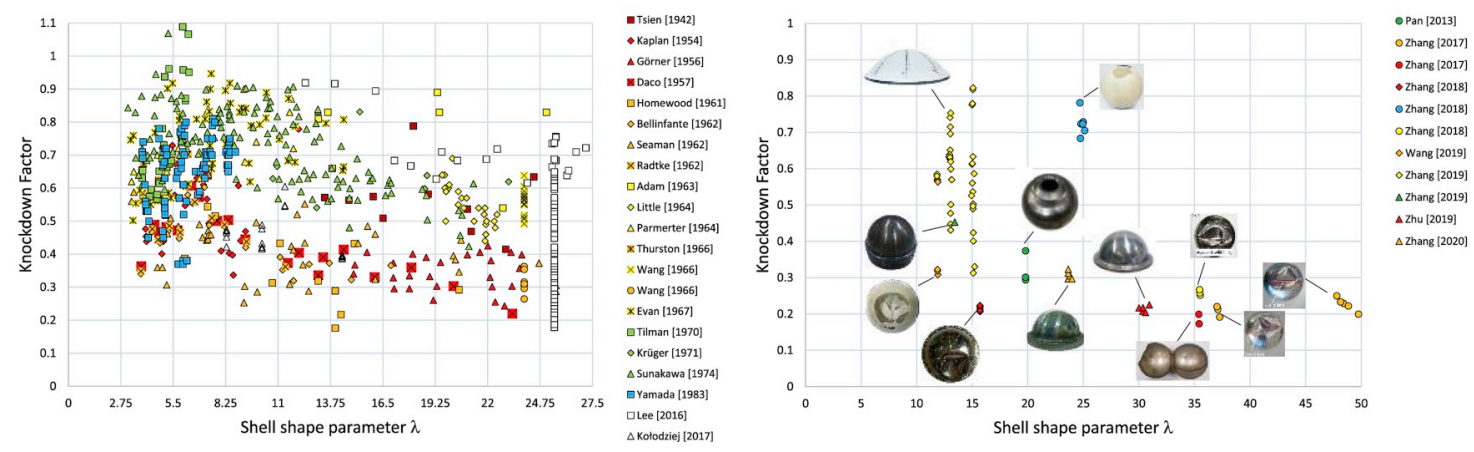

Fig. 2. Distribution of 867 experimental KDFs of spherical shells under external pressure all results are summarized in the Elsevier repository with the corresponding reference. 
presented. The third section introduces a new design concept of spherical shells and presents new analytical lower-bounds for design purposes. In section four a stiffened sphere is analyzed. The last section summarized the main results of this article and gives an outlook for future research topics.

\section{Test specimens and numerical model}

\subsection{Test specimen}

In this section a deep spherical shell is introduced, and the corresponding numerical model is presented. The geometry and material parameter for the shell are based on experiments published by Zhang et al. [31], see Table 1. Six nominal identical shells (SC shells) were manufactured and tested as shown in Fig. 3.

The outer surface of each fabricated spherical shell consists of a cap, weld seam and a heavy plate. The average buckling pressure of the test shells is $5.44 \mathrm{MPa}$ which means there is an about $77 \%$ reduction in comparison to the perfect buckling pressure according to equation (1) as shown in Table 2.

\subsection{Numerical model}

The spherical cap is modeled using S4R shell elements (with element size of $1.1 \mathrm{~mm}$ and a structured quad-dominated mesh), along with 4 triangular S3 elements, in ABAQUS [59]. Clamped boundary conditions (see Fig. 4 - left) are applied in order to impose similar boundary constraints on the shell as the weld seam and the heavy plate. However, both the heavy plate and the weld seam were removed from the CAD model in order to reduce computational effort. Geometrically nonlinear analyzes of the perfect elastic shell (GNA) are performed by using the Riks method (Static, Riks in ABAQUS).

The GNA is based on linear elastic material law but including nonlinear large deflection theory. If nonlinear elastic-plastic material behavior is considered in addition the analysis is defined as geometrically and materially nonlinear analysis (GMNA). An analysis with explicitly includes imperfections (i.e. the geometry of the middle surface includes unintended deviation from the ideal shall shape) and treating the material as linear elastic is defined as geometrically nonlinear elastic analysis with imperfections (GNIA). A combination of GNIA and nonlinear elastic-plastic material law is defined as geometrically and materially nonlinear analysis with imperfections (GMNIA).

The imperfection in this case are the measured geometric imperfection (which were caused by the stamping, cutting and welding process) of the deep spherical caps as shown in Fig. 5. The geometrical shapes of the spherical caps were obtained by using optical scans and the resulting point cloud was transformed into a numerical model [31]. The largest deformations occur next to the weld seam at the base of the cap.

The buckling pressure of this shell with MGI is on average about $12.93 \mathrm{MPa}$ which means there is a $45 \%$ reduction in comparison to the analytic buckling pressure. The test buckling pressures of the test shells

Table 1

Geometry and material data (304 stainless steel) for the deep spherical shell after [31].

\begin{tabular}{ll}
\hline & SC - Shells \\
\hline $\begin{array}{l}\text { Material parameter } \\
\text { elasticity modulus E - [MPa] }\end{array}$ & \\
Poisson's ratio $\boldsymbol{\nu}$ & 159208 \\
Yield Stress Y - [MPa] & 0.291 \\
Geometry parameter & 335 \\
Radius R - [mm] & \\
$\boldsymbol{\varphi}$ & 90.51 \\
Wall thickness t - [mm] & $53.75^{\circ}$ \\
$\lambda$ & 1 \\
$\boldsymbol{\beta}$ & 15.7 \\
\hline
\end{tabular}

ranges from 5.28 to $5.64 \mathrm{MPa}$ which is due to plastic buckling. If MGI and perfect-plastic material are considered in the simulations, the test results can be approximated very well as shown in Fig. 6 (error $<1 \%$ ).

The real buckling pressures of the test shells can be approximated very well if measured geometric imperfection are considered in the numerical model. However, this methodology has some major issues. First, it depends on high-fidelity experimental results which are not available in the early design phase. Second, the optical measurements of the geometrical shapes are time consuming and expensive.

Therefore, design methods which rely on imperfections measurements are not suitable for industrial purposes which require fast and simple design guidelines. A design methodology which is not dependent on imperfections measurements is therefore required for state-of-the-art shell design. Next, a design approach which is independent from imperfection measurements is presented and used to analyze the deep spherical dome.

\section{A new design concept for spherical shells under external pressure}

The influence of real measured geometric imperfections (MGI) on the buckling pressure of a spherical shells can be assessed very well nowadays as shown for example in studies by Zhang et al. [26] or Lee at al. [60]. However, in order to study the influence of MGI, shell structures have to be built and the imperfections have to be measured using optical measurement systems. This process is not only time consuming but also expensive.

An alternative approach to assess the imperfection sensitivity of complex shell structures is the application of perturbation or lowerbound methods like the reduced stiffness method (RSM). The RSM is applied in order to quantify the influence of so called "worst" imperfections and should deliver a theoretical plateau for the buckling load which is equal or less to every buckling load caused by multiple or largeamplitude imperfections. Studies for the application of the RSM to spherical shells under external pressure are for example given in Ref. [61].

\subsection{Reduced stiffness analysis}

The reduced stiffness method (RSM) was developed by Croll et al. [62] and its main purpose is to determine a lower-bound for the buckling load of thin-walled shells [63]. The physical background of the reduced stiffness analysis can be summarized according to Croll et al. [64] as follows:

1. The membrane energy of a shell may be eroded due to the presence of imperfections.

2. The loss of the initially stabilizing membrane energy in a prospective buckling mode is responsible for the buckling load reduction.

3. The bending energy contribution to the imperfection sensitivity is negligible

4. A lower-bound to the buckling load into a particular buckling mode will be provided by an analysis which excluded the membrane energy.

In this section, a variant of the reduced stiffness method (RSM) is introduced. This variant is a further development of cutout approach from Ref. [65] and is defined as localized reduced stiffness method (LRSM) $[66,67]$. The LRSM is based on geometrically nonlinear analyses (GNA) which as opposed to the RSM does not require the use of the first buckling eigenmode. Similarly, to the RSM, the membrane stiffness components are eliminated from the shell, and only the bending stiffness remains. However, unlike the RSM, the membrane stiffness in the LRSM is reduced in a localized fashion rather than globally.

A schematic representation of the region considered for reducing the membrane stiffness in a spherical shell is shown in Fig. 7. The spherical 

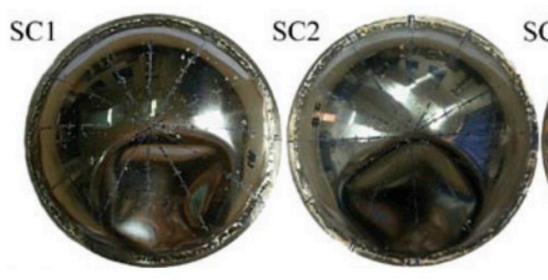
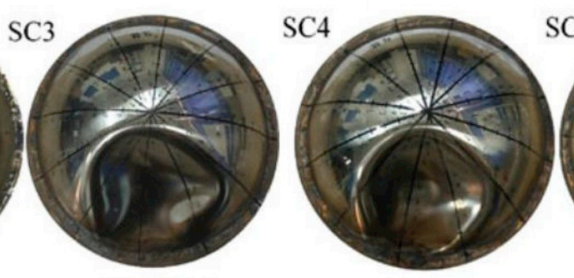

$\mathrm{SC} 6$

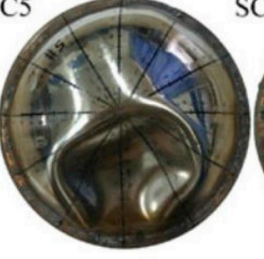

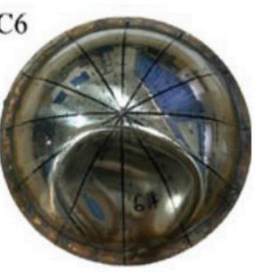

Fig. 3. Test shells SC1-SC6 after testing.

Table 2

Buckling pressure values for deep sphere.

\begin{tabular}{lll}
\hline Method & Buckling Pressure [MPa] & Knockdown Factor \\
\hline Equation (1) - $\mathrm{P}_{\text {per }}$ & 23.456 & 1.000 \\
Equation (2) - Pyield & 7.401 & 0.315 \\
Test specimen 1 & 5.280 & 0.225 \\
Test specimen 2 & 5.553 & 0.236 \\
Test specimen 3 & 5.255 & 0.224 \\
Test specimen 4 & 5.580 & 0.237 \\
Test specimen 5 & 5.356 & 0.228 \\
Test specimen 6 & 5.647 & 0.240 \\
GNA & 18.999 & 0.811 \\
GMNA & 6.802 & 0.290 \\
GNIA - (average) & 12.930 & 0.551 \\
GMNIA - (average) & 5.270 & 0.224 \\
\hline
\end{tabular}

shell has two sections, the main shell surface (green in Fig. 7), and a reduced membrane stiffness surface (white in Fig. 7). On one side, the main shell stiffness is modeled in ABAQUS by using the general shell stiffness definition (homogenous shell thickness or composite stacking). On the other side, the reduced membrane stiffness surface is modeled using the ABD - general shell stiffness matrix and all 9 components of the A - membrane matrix are divided by the membrane stiffness reduction factor $\alpha$. From studies in Ref. [68] it was concluded that $\alpha=10$ leads to conservative buckling pressure estimations for $\lambda=3 \ldots 30$ which covers the relevant design space for the elastic buckling of spherical shells under external pressure. All the components of the B coupling matrix are for isotropic shells equal to 0 . If a composite shell is analyzed with the LRSM, all the components of the B matrix should be set to 0 for the reduced membrane stiffness surface in order to prevent a singular stiffness matrix.

Also, the area of the reduced membrane stiffness surface in incrementally increased by increasing the radius Rs so its influence on the buckling load can be studied. The KDF as a function of the size of the LRSM surface (represented by the LRSM radius to base radius ratio, Rs/ r) is shown in Fig. 8 (left).

The LRSM curve for an asymmetric imperfection placement (halfway between shell apex and shell edge) is shown in Fig. 8 (left). This curve has basically 2 sections, in the first area the KDF for the buckling pressure reduces as the Rs/r ratio increases. In the second area, the KDF for the buckling pressure is constant although the size of the imperfection increases. The plateau buckling pressure of the LRSM corresponds to an average KDF of about 0.214 .

A more rigorous approach is the application of a cutout instead of a reduced membrane stiffness surface as shown in Fig. 8 (right). Cutouts remove the membrane and the bending stiffness of a spherical dome completely. The LRSM only reduces the membrane stiffness and doesn't influence of the bending stiffness. However, the lower-bound curves for both methods are the very similar.

The plateau buckling pressure vs the load increment is shown for the LRSM and the cutout approach in Fig. 9. The slope of the buckling pressure function is the same for both imperfection types. However, after the point of buckling, the pressure reduces for the LRSM analysis while the pressure for the cutout analysis approaches a plateau and even slightly increases.

In the case of the LRSM, global buckling occurs (the reduced membrane stiffness surface buckles). For the cutout method, the first failure mode is local buckling along the cutout edges and the shell can still be slightly loaded with pressure. At load increment 1.5, a dimple forms near the cutout (at the apex of the shell) and global buckling occurs.

Next, the cutout \& the LRSM surface were positioned at the shell apex and the corresponding numerical results are shown in Fig. 10. The position of the cutout or the reduced membrane stiffness surface seems
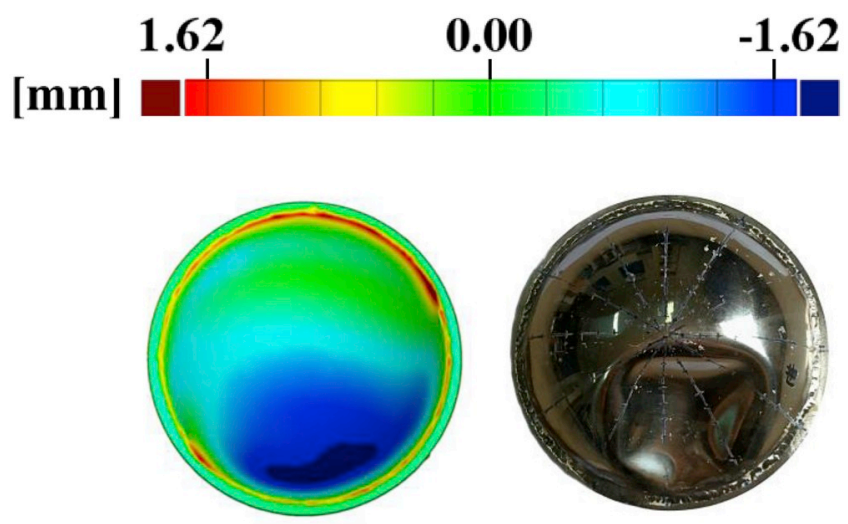

Fig. 5. Geometric Imperfection of the sphere SC1 (left) shell SC1 after testing (right).
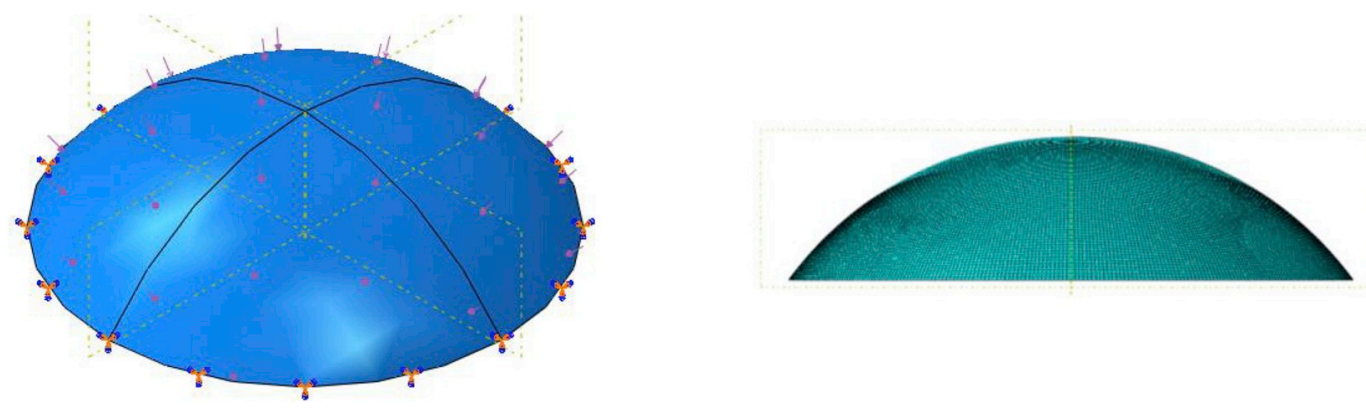

Fig. 4. Numerical model of the deep spherical shell with clamping, pressure loading (left) and mesh (right). 


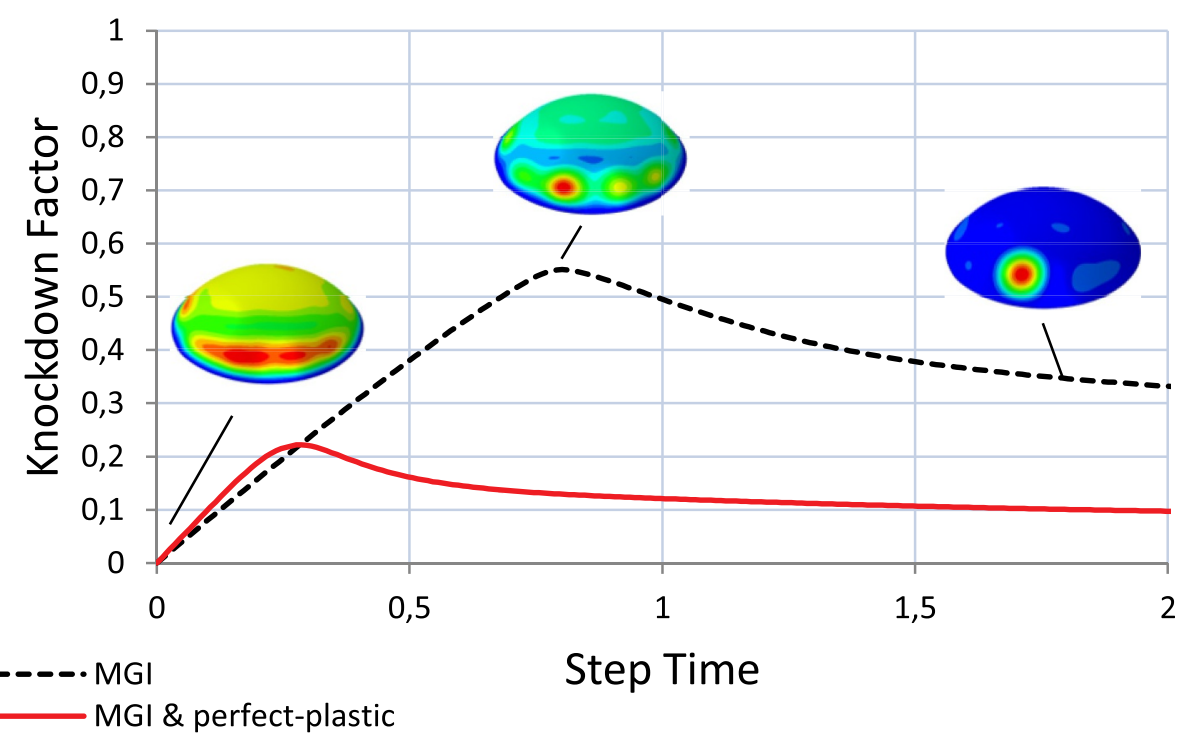

Fig. 6. Elastic and perfect-plastic buckling of a deep spherical shell under external pressure - simulation results with MGI of SC1.

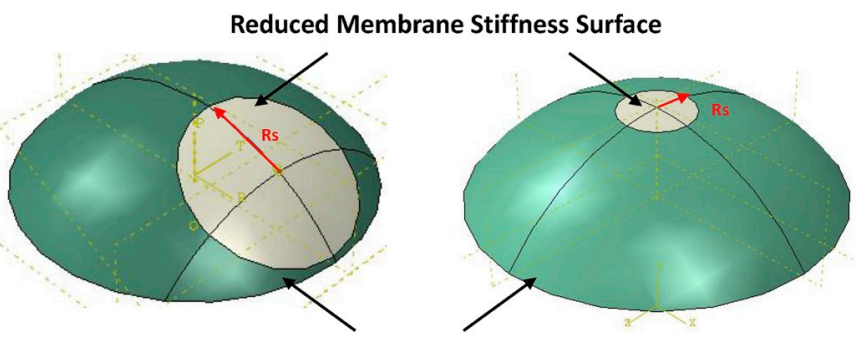

Main Shell Surface

Fig. 7. Configuration of LRSM for spherical shells in the numerical analysis: asymmetric imperfection (left) axisymmetric imperfection (right).

not to influence the lower-bound KDF significantly for this deep spherical shell because in both cases the minimum $\mathrm{KDF}=0.21$.

In this case, the LRSM curve has different nonlinear slope which consists of three different areas (compared to two areas in the asymmetric buckling example scenario above), see Fig. 10. In the first area the KDF for the buckling pressure reduces until it approaches the second area, a plateau where the $\mathrm{KDF}$ for the buckling pressure is constant although the size of the imperfection increases. The plateau buckling pressure of the LRSM corresponds to an average KDF of about 0.21. If the $\mathrm{Rs} / \mathrm{r}$ ratio is further increased, the KDF for the buckling pressure increases.

For small cutouts, there is a first plateau buckling pressure but as the size of the cutout increases the KDF for the buckling pressure decreases

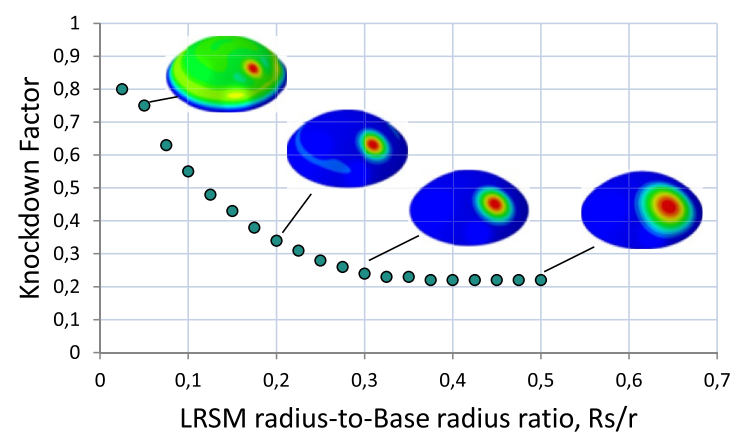

until it approaches a second plateau if the cutout-to-base radius ratio $\mathrm{CR} / \mathrm{r}$ approaches 0.55 to 0.63 . The resulting $\mathrm{KDF}$ in the plateau range equals to about 0.21 for this deep dome which is the same as the minimum KDF for the buckling pressure of the LRSM. If the CR/ $\mathrm{r}$ ratio increases further a higher "jump" buckling pressure similar to the LRSM can be determined.

The plateau buckling pressure vs the load increment for axisymmetric buckling of the deep sphere is shown in Fig. 11. The results show that the structural behavior is similar to the asymmetric buckling event shown in Fig. 9. The shell in the LRSM analysis buckles globally and the shell in the cutout analysis buckles first locally along the cutout edge and then buckles globally.

Next, the "jump" buckling pressure vs the load increment for axisymmetric buckling of the deep sphere is shown in Fig. 12. In the case of the LRSM, the edge of the reduced membrane stiffness surface buckles instead of the shell apex and the pressure load can be still slightly increased until global buckling occurs. A similar behavior occurs for the cutout analysis.

Lastly, the LRSM is performed and the yield strength is considered by using perfect-plastic material behavior (that means only the yield stress is used and the plastic strain is set to 0 ). The corresponding results are shown for axis and non-axisymmetric buckling in Fig. 13. Both LRSM variants lead to the same $\mathrm{KDF}=0.19$ which is conservative with respective to all experimental results of the testing series.

\subsection{Evaluation of experimental results from literature}

In this section buckling test results shown in Table 4 are further

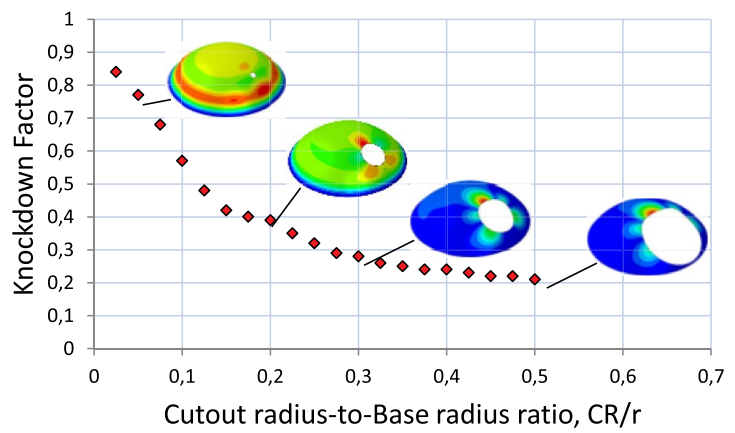

Fig. 8. KDF for asymmetric buckling pressure according to LRSM (left) and cutout (right). 

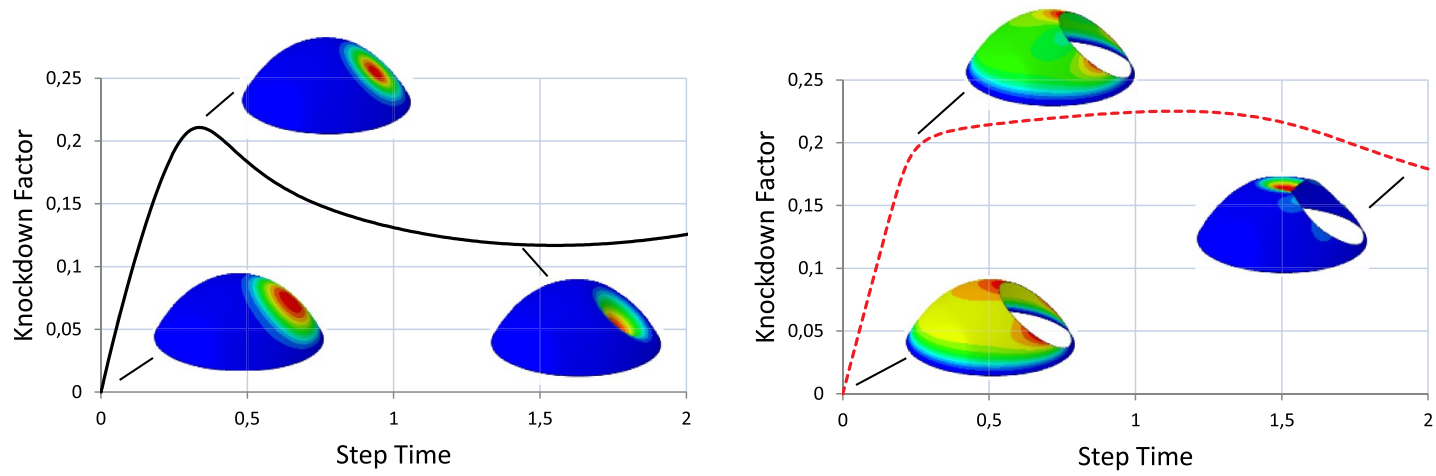

Fig. 9. KDF for the plateau buckling pressure vs. load increment of numerical analysis: asymmetric buckling - LRSM (left) and cutout (right).
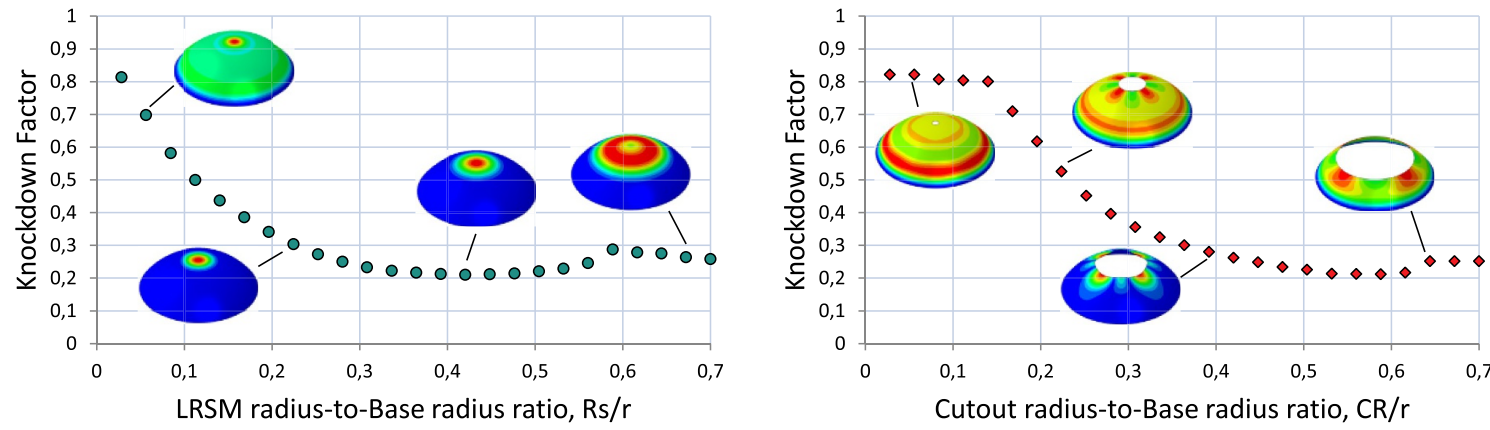

Fig. 10. KDF for axisymmetric buckling pressure according to LRSM (left) and cutout (right).
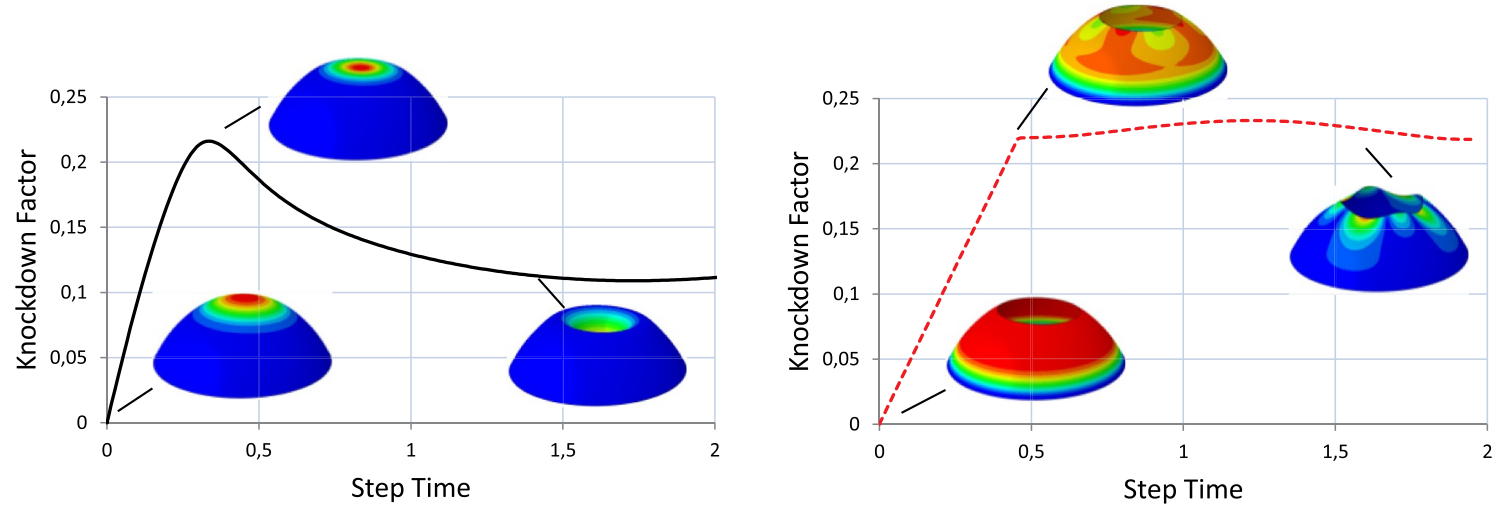

Fig. 11. KDF for the plateau buckling pressure vs. load increment of numerical analysis: axisymmetric buckling - LRSM (left) and cutout (right).
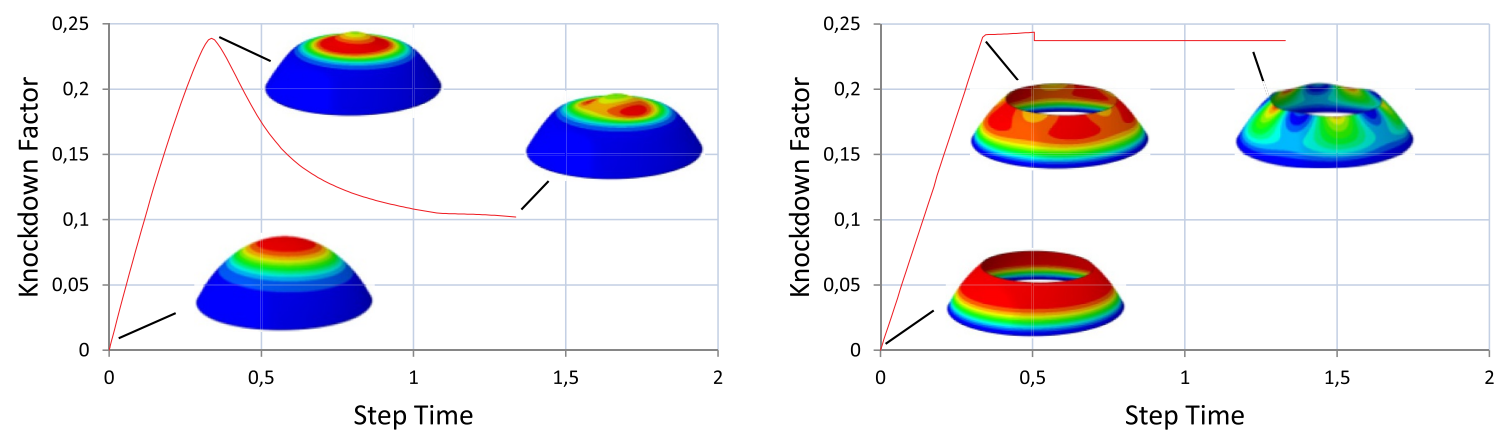

Fig. 12. KDF for the "jump" buckling pressure vs. load increment of numerical analysis: asymmetric buckling - LRSM (left) and cutout (right). 

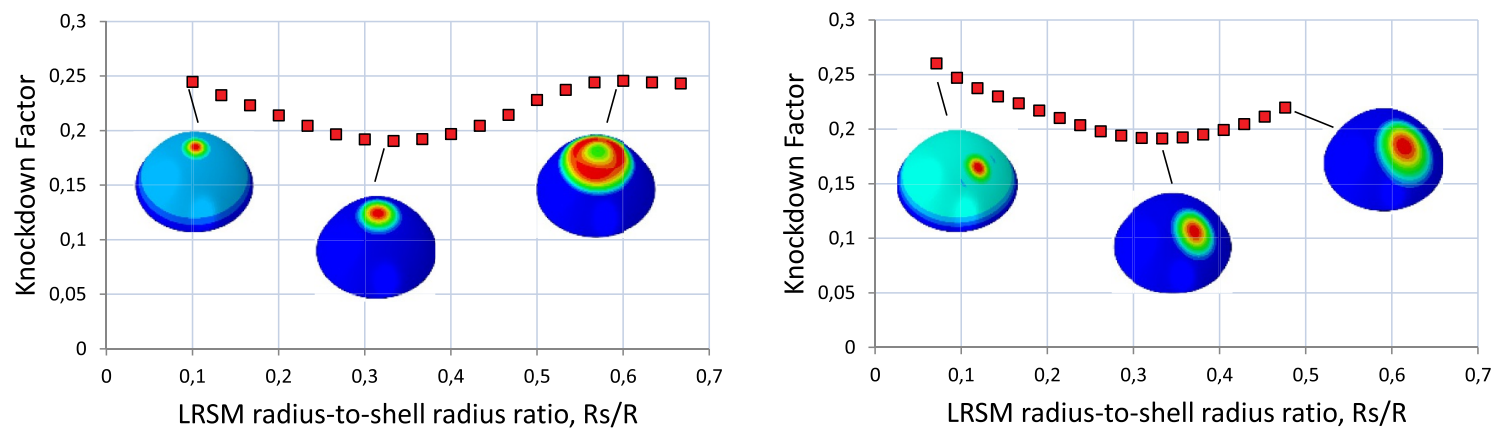

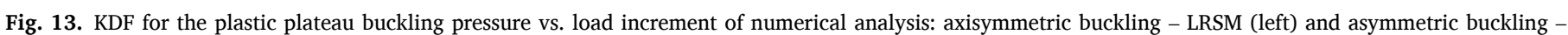
LRSM (right).

evaluated regarding their reliability for validation of design criteria. The following table has rows for the reference of the experimental study, the number of test specimen, the range for the $\mathrm{R} / \mathrm{t}, \mathrm{H} / \mathrm{r}$ and $\lambda$ parameters, the material, the ratio of yield stress to elasticity modulus and the range of the KDF values. It should be noted that a detailed overview for experimental studies is given in the excel sheet which is part of the Elsevier repository of this article. Some of the early studies on spherical shell buckling are not well described. Most of the time the material parameters (yield and elasticity modulus) are not given, there are no figures and description of the test setups or of the test specimen. Also, some references were not available to the authors (however we could extract the experimental KDFs from figures of other references). In order to be reliable for the validation purpose of this article an experimental study shall have all data which are required in Table 3. Based on the evaluation 277 (of 867) test results (32\%) are sufficiently described for the validation purposes of this article.
Table 4

Representative geometry and data for the inner dome of the LH2 tank after [94].

\begin{tabular}{|c|c|}
\hline $\begin{array}{l}\text { Material parameter - Aluminum } \\
\text { elasticity modulus } E \text { - }[\mathrm{MPa}]\end{array}$ & 80000 \\
\hline Poisson's ratio $v$ & 0.3 \\
\hline Yield stress Y - [MPa] & 400 \\
\hline \multicolumn{2}{|l|}{ Geometry parameter } \\
\hline Radius R - [mm] & 2000 \\
\hline Skin thickness t - [mm] & 3.04 \\
\hline Stiffener thickness ts - $[\mathrm{mm}]$ & 2.48 \\
\hline Stiffener height hs - [mm] & 23.48 \\
\hline $\mathrm{t}_{\mathrm{eff}}-[\mathrm{mm}]$ & 16.85 \\
\hline $\mathrm{R} / \mathrm{t}_{\mathrm{eff}}$ & $\sim 118.67$ \\
\hline$\lambda$ & $\sim 28$ \\
\hline
\end{tabular}

Table 3

Summary of experimental buckling studies for spherical shells under external pressure.

\begin{tabular}{|c|c|c|c|c|c|c|c|c|c|}
\hline Nr. & Reference & $\mathrm{n}$ & $\mathrm{R} / \mathrm{t}$ & $\mathrm{H} / \mathrm{r}$ & $\lambda$ & Material & $\mathrm{Y} / \mathrm{E}$ & KDFs & Reliable \\
\hline 1 & Bach [69] & 10 & $\mathrm{n} / \mathrm{a}$ & $\mathrm{n} / \mathrm{a}$ & $12.04-23.53$ & Steel & $\mathrm{n} / \mathrm{a}$ & $0.11-0.24$ & no \\
\hline 2 & Tsien [34] & 8 & 838-1955 & 0.2 & $15.99-24.42$ & $\mathrm{n} / \mathrm{a}$ & $\mathrm{n} / \mathrm{a}$ & $0.41-0.78$ & no \\
\hline 3 & Klöppel [18] & 44 & $432-1860$ & $0.2-0.5$ & $14.83-70.13$ & Steel & $\mathrm{n} / \mathrm{a}$ & $0.12-0.34$ & no \\
\hline 4 & Kaplan [70] & 23 & 196-956 & $0.06-0.11$ & 4.09-12.07 & Mg-alloy & 0.0046 & $0.33-0.77$ & yes \\
\hline 5 & Görner [19] & 26 & $301-762$ & 0.47 & $14.96-23.79$ & $\mathrm{n} / \mathrm{a}$ & $\mathrm{n} / \mathrm{a}$ & $0.24-0.45$ & no \\
\hline 6 & Daco [19] & 20 & $96-872$ & $0.21-0.67$ & $3.82-23.29$ & $\mathrm{n} / \mathrm{a}$ & $\mathrm{n} / \mathrm{a}$ & $0.22-0.64$ & no \\
\hline 7 & Homewood [71] & 12 & $161-1114$ & $0.11-0.24$ & $6.1-20.5$ & Al-alloy, Steel & 0.0011 & $0.17-0.54$ & yes \\
\hline 8 & Bellinfante [72] & 18 & $\mathrm{n} / \mathrm{a}$ & $\mathrm{n} / \mathrm{a}$ & $3.79-16.92$ & $\mathrm{n} / \mathrm{a}$ & $\mathrm{n} / \mathrm{a}$ & $0.31-0.60$ & no \\
\hline 9 & Seaman [73] & 39 & $516-1740$ & $0.03-0.18$ & $4.67-25.6$ & PVC & 0.0096 & $0.25-0.55$ & yes \\
\hline 10 & Radtke [74] & 12 & $\mathrm{n} / \mathrm{a}$ & $\mathrm{n} / \mathrm{a}$ & $4.4-11.38$ & $\mathrm{n} / \mathrm{a}$ & $\mathrm{n} / \mathrm{a}$ & $0.36-0.70$ & no \\
\hline 11 & Adam [19] & 8 & 244-577 & $0.3-1$ & $13.11-43.11$ & PVC & 0.0171 & $0.54-0.89$ & yes \\
\hline 12 & Krenzke [75] & 70 & $10-212$ & $0.072-1$ & $1.58-33.18$ & Aluminium & 0.0074 & $0.11-0.90$ & yes \\
\hline 13 & Parmerter [76] & 22 & $744-4262$ & $0.04-0.10$ & $4.67-11.8$ & Cooper & $\mathrm{n} / \mathrm{a}$ & $0.63-0.90$ & no \\
\hline 14 & Little [77] & 24 & $572-753$ & 0.26 & $19.6-22.49$ & PVC & 0.015 & $0.46-0.69$ & yes \\
\hline 15 & Thurston [68] & 10 & $\mathrm{n} / \mathrm{a}$ & $\mathrm{n} / \mathrm{a}$ & $3.88-5.43$ & $\mathrm{n} / \mathrm{a}$ & $\mathrm{n} / \mathrm{a}$ & $0.56-0.70$ & no \\
\hline 16 & Wang [78] & 23 & 666 & 0.26 & 23.92 & PVC & $\mathrm{n} / \mathrm{a}$ & $0.26-0.63$ & no \\
\hline 17 & Carlson [47] & 27 & $1328-2833$ & 1 & 135-198 & Steel & $\mathrm{n} / \mathrm{a}$ & $0.17-0.86$ & no \\
\hline 18 & Evan [79] & 50 & $\mathrm{n} / \mathrm{a}$ & $\mathrm{n} / \mathrm{a}$ & $3.4-14.43$ & $\mathrm{n} / \mathrm{a}$ & $\mathrm{n} / \mathrm{a}$ & $0.55-0.94$ & no \\
\hline 19 & Tilman [80] & 30 & $388-1557$ & $0.04-0.08$ & $3.89-6.32$ & PVC & $\mathrm{n} / \mathrm{a}$ & $0.56-1.08$ & no \\
\hline 20 & Krüger [68] & 7 & $\mathrm{n} / \mathrm{a}$ & $\mathrm{n} / \mathrm{a}$ & $10.72-23.10$ & $\mathrm{n} / \mathrm{a}$ & $\mathrm{n} / \mathrm{a}$ & $0.54-0.83$ & no \\
\hline 21 & Sunakawa [81] & 143 & $193-1442$ & $0.03-0.15$ & $3.12-9.44$ & PVC & $\mathrm{n} / \mathrm{a}$ & $0.59-1.06$ & no \\
\hline 22 & Yamada [82] & 79 & 259-2552 & $0.03-0.10$ & $3.86-8.32$ & PVC & $\mathrm{n} / \mathrm{a}$ & $0.37-0.81$ & no \\
\hline 23 & Blachut [83] & 6 & $320-853$ & $0.03-0.07$ & $3.35-5.04$ & Steel & 0.0015 & $0.48-0.62$ & yes \\
\hline 24 & Pan [84] & 4 & $25-26$ & 1 & 19.8 & Titan & 0.0084 & $0.29-0.30$ & yes \\
\hline 25 & Lee [60] & 61 & $43-122$ & 1 & $16-27$ & VPS & $\mathrm{n} / \mathrm{a}$ & $0.17-0.89$ & no \\
\hline 26 & Kolodziey [85] & 20 & $333-1000$ & 0.126 & $8.29-14.36$ & Steel & 0.0013 & $0.38-0.60$ & yes \\
\hline 27 & Zhang [26] & 10 & $103-185$ & 1 & $37-49$ & Steel & 0.0012 & $0.19-0.24$ & yes \\
\hline 28 & Zhang [31] & 6 & 90.5 & 0.5 & 15.7 & Steel & 0.0021 & $0.20-0.23$ & yes \\
\hline 29 & Zhang [32] & 1 & 26 & 1 & 13.4 & Steel & 0.011 & 0.45 & yes \\
\hline 30 & Wang [86] & 6 & 45 & 0.54 & 11.85 & SOMOS 8000 & 0.0104 & $0.30-0.57$ & yes \\
\hline 31 & Zhang [87] & 38 & $45-75$ & 0.54 & $11-15$ & SOMOS 8000 & 0.0104 & $0.31-0.82$ & yes \\
\hline 32 & Zhu [88] & 5 & $136-144$ & 1 & 30 & Steel & 0.0106 & $0.20-0.22$ & yes \\
\hline 33 & Zhang [89] & 5 & $84-85$ & 1 & 23.6 & Steel & 0.0055 & $0.29-0.32$ & yes \\
\hline
\end{tabular}




\subsection{Design criterion and validation}

In this section the LRSM design curve is compared with experimental results from literature, see Fig. 14 (left). This diagram shows the ratio of experimental buckling stress to yield stress vs. the square root of yield stress to "perfect" buckling stress (also defined as slenderness $\lambda_{s}$ ). Spherical shells with large slenderness ratios $\left(\lambda_{\mathrm{s}}>\sqrt{3} \approx 1.73\right)$, buckle elastically. Plastic buckling occurs when the "perfect" buckling stress approaches the yield stress $\left(\lambda_{s} \sim 1\right)$. The structural behavior between elastic and plastic buckling can be characterized as elastic-plastic buckling. The analytical perfect solution is shown as a red line in Fig. 14. The LRSM lower-bound was determined for a hemi-sphere and is also shown in Fig. 14 and given by equation (6). Note that the goodness of fit parameter R-square $=0.9986$. If equation (6) is modified it can be used to determine a design KDF according to the LRSM which considers plastic buckling, see equation (7). The KDF according to equation (7) equals to about 0.2 for shells which buckle in the elastic region and seems to be independent of the R/t ratio. Similar findings were reported by Hutchinson [90].

$$
\begin{aligned}
& F\left(\lambda_{s}\right)=\frac{\sigma_{\text {exp }}}{\sigma_{\text {yield }}}=\frac{p_{1} \cdot \lambda_{s}^{3}+p_{2} \cdot \lambda_{s}^{2}+p_{3} \cdot \lambda_{s}+p_{4}}{\lambda_{s}^{3}+q_{1} \cdot \lambda_{s}^{2}+q_{2} \cdot \lambda_{s}+q_{3}} \\
& p_{1}=-0.008571, p_{2}=0.07207, p_{3}=0.03053, p_{4}=0.01944 \\
& q_{1}=-0.6903, q_{2}=0.2393, q 3=0.0002345 \\
& K D F_{\text {LRSM }}=F\left(\lambda_{s}\right) \cdot \frac{\sigma_{\text {yield }}}{\sigma_{\text {per }}}, \text { for } 0.2 \leq \lambda_{s} \leq 6
\end{aligned}
$$

It should be noted that the values of the LRSM design curves depends in this illustration on the $\mathrm{H} / \mathrm{r}$ ratio of the spherical cap. A conservative estimation for all kinds of spherical domes should be achievable with the LRSM lower-bound for hemi-spheres (because the imperfection sensitivity increases as the spherical cap becomes deeper). This design curve is the most relevant for deep-sea submersible shells which are rather deep. When compared with the relevant experimental results from section 3.2, it shows that the LRSM lower-bound (hemi-sphere) delivers for all shells a conservative buckling stress estimation except for two cases. An experimental result for a complete sphere by Zhang and a experimental result by Homewood which is considered as an outliner due to probable poor realized clamping conditions as discussed by for example Wang et al. [78] and Wagner et al. [65]. Also, for the purpose of comparison the results are compared with the PD 5500 in Fig. 14 (right). The LRSM delivers significantly higher design factors than the PD 5500 and is still conservative with respect to the experimental results.

\subsection{Summary of results}

The results according to equations (6) and (7) are summarized in Fig. 15 along with the test results and are also compared with alternative design concepts according to the PD 5500 [91] and the reference resistance design (RRD) after [92]. The results show that the design curve according to the PD 5500 delivers to conservative estimations for the buckling pressure of this shell. The design according to Eurocode is not always conservative for the deep spherical caps. The LRSM is conservative with respect to all experimental results and yet delivers significantly higher design factors than the PD 5500.

\section{Practical application}

Based on the results of section 3, it is concluded that the LRSM represents promising new design concept for spherical shells under external pressure. In this section, a shell buckling example is given which even today hard to analyze. In this section the LRSM is applied to the inner dome of the cryogenic upper stage ESC-A of the Ariane 5 launch-vehicle, see Fig. 16.

The inner dome of the LH2 tank is an orthogrid-stiffened spherical shell with a radius of $2000 \mathrm{~mm}$ and a non-stiffened pole cap. Studies for similar spherical shells are given by Wang in Ref. [95]. The geometry and material parameters of a representative inner dome model are given in Table 4.

The analytical equation according to Zoelly cannot not be applied for this heavily stiffened sphere in order to calculate the reference buckling pressure. A series of complex analytical equations to calculate the buckling pressure of the "perfect" stiffened sphere are given in Ref. [93].

Within this article the finite element method is used to analyze this complex grid stiffened hemi-sphere. The numerical model consists of 492266 linear shell elements (S4R in ABAQUS [59]) with clamped mechanical boundary conditions; see Fig. 17. This shell exhibits local skin buckling near the pole as a first failure mode at about $0.49 \mathrm{MPa}$ and shortly afterwards global buckling ( $0.72 \mathrm{MPa})$ which is caused by a localized single dimple near the clamping edges, see Fig. 18 (left).

In order to determine an equivalent knockdown factor, the effective thickness $t_{\text {eff }}$ [96] of the stiffened sphere is required, see equation (11). The effective thickness $t_{\text {eff }}$ of each section can be approximated based on the membrane $\left(A_{11} \& A_{22}\right)$ and bending stiffness's $\left(D_{11} \& D_{22}\right)$.
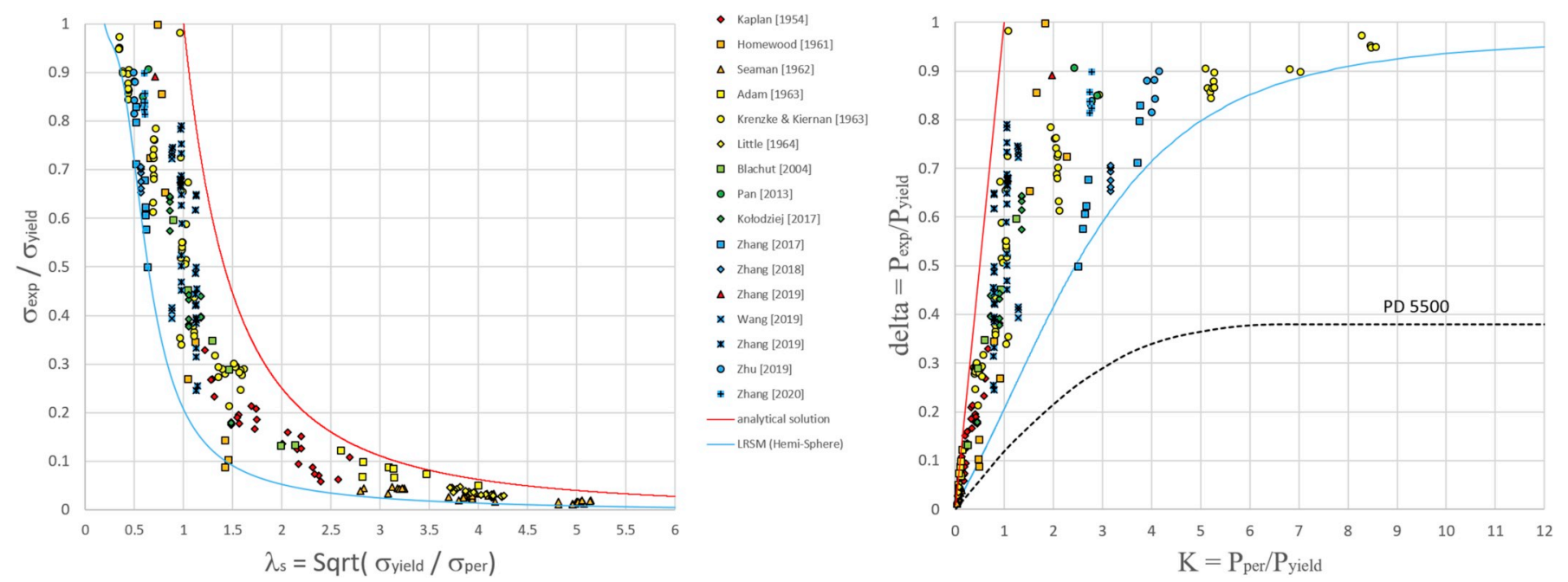

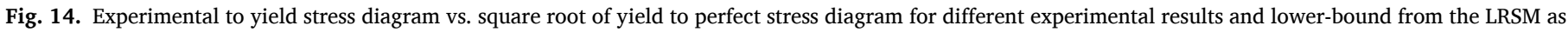
well as analytical solution (left) comparison of PD 5500 with LRSM (right). 


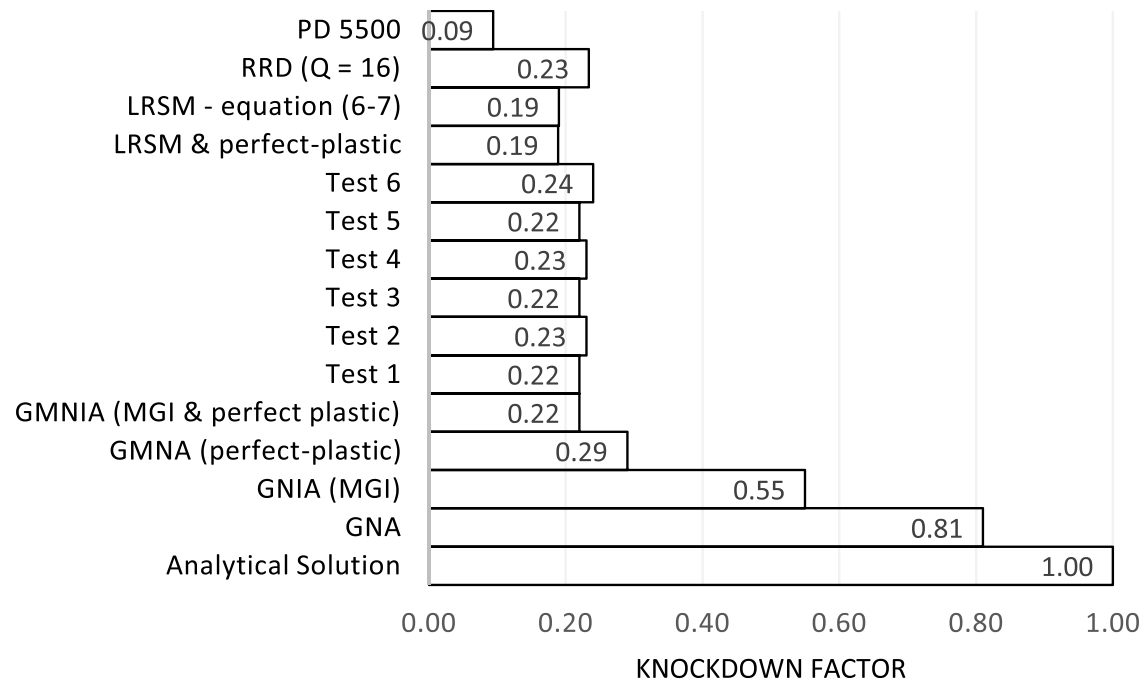

Fig. 15. KDF of the spherical shells with $\lambda=15.7$ according to experimental results and different design concepts.
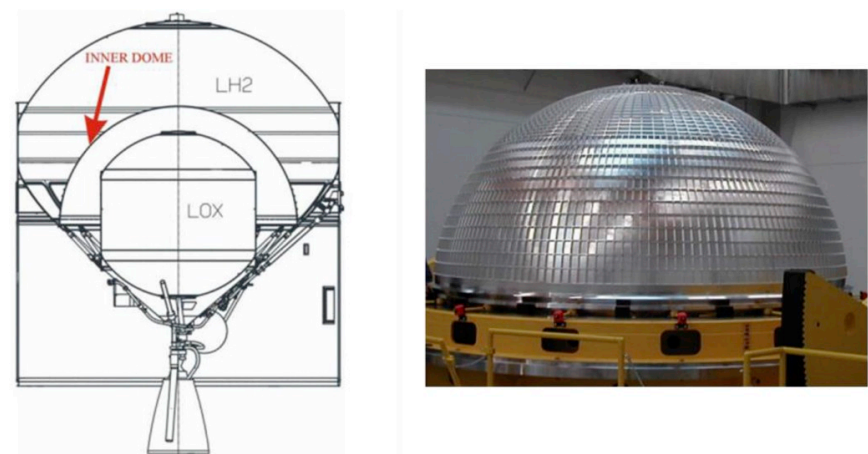

Fig. 16. Cryogenic upper stage ESC-A of Ariane 5 [93] (left) Inner dome of the LH2-tank for the ESC-A [94] (right).

$\mathrm{t}_{\mathrm{eff}}=\left(\frac{144 \cdot \mathrm{D}_{11} \cdot D_{22}}{A_{11} \cdot A_{22}}\right)^{\frac{1}{4}}$

The inner dome has five sections with different stiffener pattern and the pole cap, see Fig. 19.

For conservative design the effective thickness of the first section $t_{\text {eff }}$ $=16.85 \mathrm{~mm}$ is used (section 1 has largest share of the inner dome and is the most prone to buckling due to the large radius).

The LRSM was performed for the inner dome (see Fig. 18 - right) and the LRSM surface was only applied to the skin of the stiffened shell and was positioned halfway between shell edge and dome cap. The stiffeners are not affected by the LRSM surface as they are not imperfection sensitive. The resulting knockdown factor for this stiffened hemi-sphere equals to 0.47 which is about $134 \%$ higher compared to the knockdown factor for a similar $(\mathrm{R} / \mathrm{t} \sim 118)$ unstiffened hemi-sphere, see Table 5.

\section{Conclusion and outlook}

This article starts with a literature review regarding the buckling of spherical shells under external pressure. Based on the introduction the need for robust and reliable design methods for spherical shells is identified. Because existing design rules like NASA-SP 8032 give very conservative design loads for isotropic spherical shells.

A series of 6 deep spherical shells is analyzed in this article, the shells have $\mathrm{H} / \mathrm{r} \sim 0.5, \mathrm{R} / \mathrm{t} \sim 90$ and $\lambda \sim 15.7$. Geometrically nonlinear analyses with measured geometric imperfections and perfect-plastic material behavior were performed to approximate the experimental knockdown factors which range from $0.22 \ldots 0.24$.

Based on this design example for spherical shells, the need for robust and reliable design method (which is independent from expensive imperfection measurements) is identified. Also, existing design rules like NASA-SP 8032 give very conservative design loads for isotropic spherical shells.

A variant of the reduced stiffness method is presented which eliminates locally the membrane stiffness of a spherical shell and leads to a lower-bound for the buckling pressure. This localized reduced stiffness method (LRSM) is applied to a set of deep spherical domes with clamped edge conditions.

A series of numerical analysis is performed to understand to lowerbound behavior of spherical shells burdened by localized imperfection surfaces. The LRSM leads to a lower-bound KDF $=0.21$ in the case of

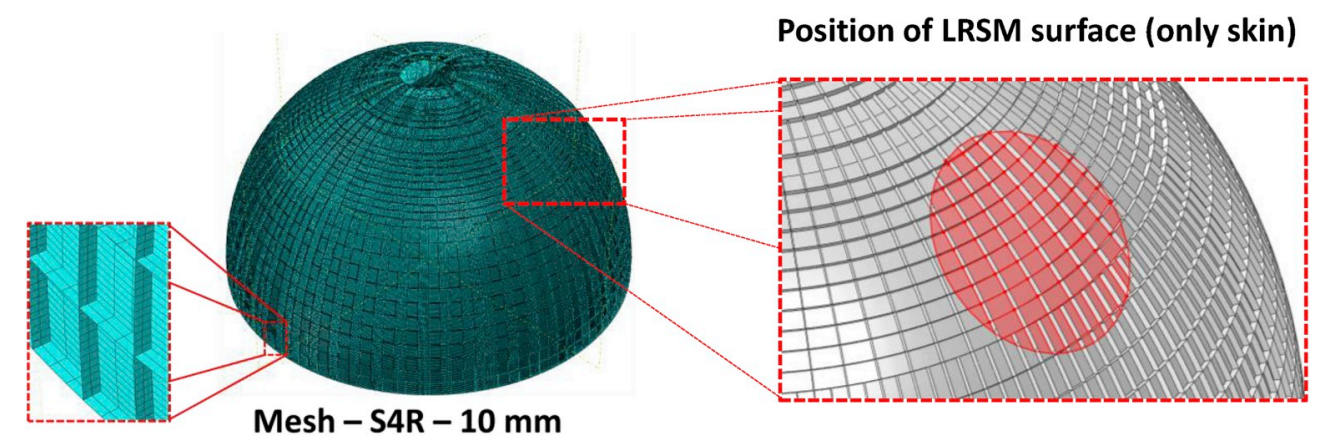

Fig. 17. Numerical model of the inner dome: Mesh (left) LRSM surface position (right). 

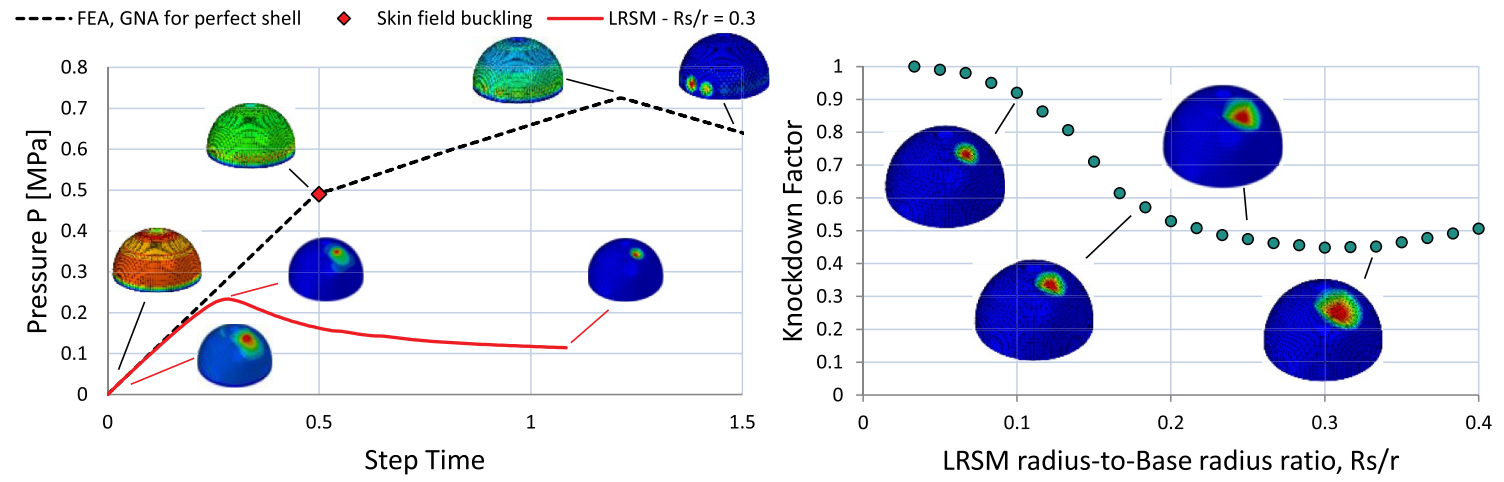

Fig. 18. Pressure vs. step time (left) LRSM diagram of the inner dome (right).

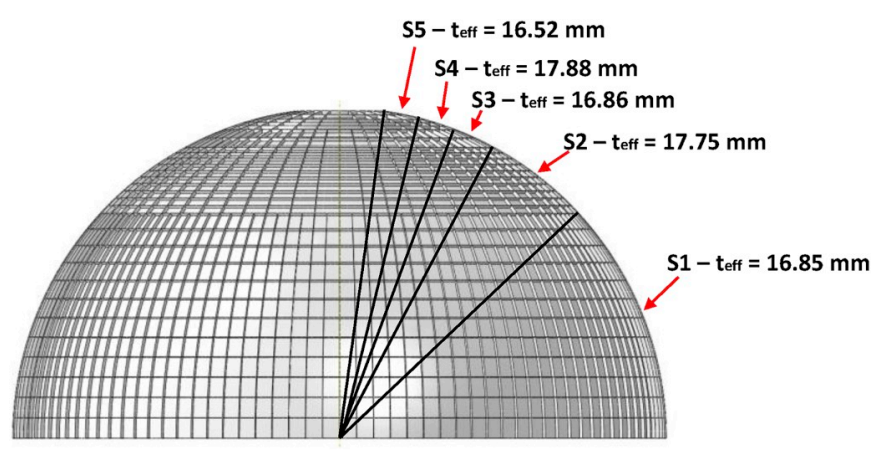

Fig. 19. Different sections of the inner dome.

Table 5

Buckling pressure and KDFs for the inner dome.

\begin{tabular}{lll}
\hline Method & Buckling Pressure [MPa] & Knockdown Factor \\
\hline GNA (global buckling) & 0.72 & - \\
GNA (local skin buckling) & 0.49 & 1.00 \\
LRSM - stiffened & 0.23 & 0.47 \\
LRSM - unstiffened & 0.10 & 0.20 \\
NASA SP-8032 & 0.07 & 0.14 \\
\hline
\end{tabular}

elastic buckling and a KDF $=0.19$ in the case of perfect-plastic buckling which is conservative for all experimental results.

Compared to probabilistic methods [97], the measurement, stochastic analysis and storage of imperfection data from a large number of tests is not needed if the LRSM is applied which saves time and cost during the design process.

The LRSM was applied to real sphere shell structures: an orthogrid stiffened hemi-sphere. The LRSM is simple to realize in FEA (even for complex sub- and full-scale shell structures) and delivers promising design loads. The new concept shall be further expanded to torispherical shells under external pressure [98] and internal pressure [99] as well as composite shells [100] which may suffer from delamination imperfections as recently shown be Wang et al. [101].

\section{Acknowledgments}

This study was supported by the Excellent Youth Foundation of Jiangsu Province [Grant number: BK20190103], the Six Talent Peaks Project of Jiangsu Province [Grant number: KTHY-068], and the National Natural Science Foundation of China [Grant number: 51709132].

\section{References}

[1] R. Zoelly, Über ein Knickungsproblem an der Kugelschale, Zürich, 1915.
[2] A. van der Neut, De Elastische Stabiliteit Van Den Dunwandigen bol, Dissertation, Delft., 1932.

[3] S. Pranesh, D. Kumar, V. Subramanian, D. Sathianarayanan, G. Ramadass, Nonlinear buckling analysis of imperfect thin spherical pressure hull for manned submersible, J. Ocean Sci. Eng. 2 (4, December) (2017) 293-300.

[4] D. Bushnell, Buckling of shells—pitfall for designers, AIAA J. 19 (9) (1981) 1183-1226.

[5] H. Karimi, I. Kani, Finding the worst imperfection pattern in shallow lattice domes using genetic algorithms, J. Build Eng. 23 (May) (2019) 107-113.

[6] V. Jampani, D. Mulder, K. De Sousa, A. Gélébart, J. Lagerwall, A. Schenning, Micrometer-scale porous buckling shell actuators based on liquid crystal networks, Adv. Funct. Mater. 28 (31) (2018).

[7] W. Yang, J. Yang, Y. Dong, S. Mao, Z. Gao, Z.e. a. Yue, Probing buckling and postbuckling deformation of hollow amorphous carbon nanospheres: in-situ experiment and theoretical analysis, Carbon 137 (October) (2018) 411-418.

[8] M. Haboussi, A. Sankar, M. Ganapathi, Nonlinear axisymmetric dynamic buckling of functionally graded graphene reinforced porous nanocomposite spherical caps, Mech. Adv. Mater. Struct. (2018), https://doi.org/10.1080/ 15376494.2018.1549296.

[9] L. Zhang and C. Ru, "Post-buckling of a pressured biopolymer spherical shell with the mode interaction".Proceedings of the Royal Society A: Mathematical, Physical and Engineering Sciences.

[10] Y.-L. Zhang, J. Jin, H.-L. Hou, S.-Y. Liu, X.-L. Wei, The buckling strength of plexiglass protective shield under static water pressure, Eng. Fail. Anal. 99 (2019) 169-179.

[11] A. Khan, W. Liquan, W. Gang, M. Imran, H. Waqas, A. Zaidi, Concept design of the underwater manned seabed walking robot, J. Mar. Sci. Eng. 7 (2019) 366.

[12] A. Zingoni, Liquid-containment shells of revolution: a review of recent studies on strength, stability and dynamics, Thin-Walled Struct. 87 (2015) 102-114.

[13] S. Eggwertz, L. Samuelson, Buckling strength of spherical shells, J. Constr. Steel Res. 17 (3) (1990) 195-216.

[14] J. Thompson, The Elastic Instability of Spherical Shells, PhD Dissertation, Cambridge University, September 1961, p. 1961.

[15] J. Thompson, J. Sieber, Shock-sensitivity in shell-like structure: with simulations of spherical shell buckling, Int. J. Bifurcation Chaos 26 (2016) 25, 1630003.

[16] J. Sanders, Nonlinear shell theories for thin shells, Q. Appl. Math. 21 (1963) 21-36, https://doi.org/10.1090/qam/147023.

[17] J. Thompson, The rotationally-symmetric branching behaviour of a complete spherical shell, Proc. R. Neth. Acad. Sci. 67 (1964) 295-311.

[18] K. Kloppl, O. Jungbluth, Beitrag zum durchschlag-problem duennwandiger kugelschalen, Stahlbau 22 (1953) 121-130.

[19] H. Adam, P. King, Experimental investigation of the stability of monocoque domes subjected to external pressure, Exp. Mech. 5 (1965) 313-320.

[20] I. Elishakoff, Resolution of the Twentieth Century Conundrum in Elastic Stability, World Scientific, Singapore, 2014.

[21] I. Elishakoff, Probabilistic resolution of the twentieth century conundrum in elastic stability, Thin-Walled Struct. 59 (2012) 35-57.

[22] O. Ifayefunmi, J. Błachut, Imperfection sensitivity: a review OF buckling behaviour OF cones, cylinders and domes, J. Press. Vessel Technol. (2018), https://doi.org/10.1115/1.4039695. Accepted manuscript.

[23] J. Zhang, M. Wang, W. Wang, W. Tang, Buckling of egg-shaped shells subjected to external pressure, Thin-Walled Struct. 113 (2017) 122-128.

[24] J. Zhang, B. Zhu, F. Wang, W. Tang, W. Wang, Z. Meng, Buckling of prolate eggshaped domes under hydrostatic external pressure, Thin-Walled Struct. 119 (2017) 296-303.

[25] M. Wang, J. Zhang, W. Wang, W. Tang, Linear and nonlinear elastic buckling of stereolithography resin egg-shaped shells subjected to external pressure, ThinWalled Struct. 127 (2018) 516-522.

[26] J. Zhang, M. Zhang, T. Wenxian, W. Weibo, W. Minglu, Buckling of spherical shells subjected to external pressure: a comparison of experimental and theoretical data, Thin-Walled Struct. 111 (2017) 58-64.

[27] J. Zhang, W. Wang, W. Cui, W. Tang, F. Wang, Y. Chen, Buckling of longanshaped shells under external pressure, Mar. Struct. 60 (2018) 218-225. 
[28] J. Zhang, W. Wang, F. Wang, W. Tang, W. Cui, W. Wang, Elastic buckling of externally pressurized Cassini oval shells with various shape indices, Thin-Walled Struct. 122 (2018) 83-89.

[29] D. Holmes, J. Lee, H. Park and M. Pezzulla, "The Nonlinear Buckling Behavior of a Complete Spherical Shell under Uniform External Pressure and Homogenous Natural Curvature".arXiv:1810.04078 [cond-mat.soft].

[30] M. Zhang, W. Tang, F. Wang, J. Zhang, W. Cui, Y. Chen, Buckling of bi-segment spherical shells under hydrostatic external pressure, Thin-Walled Struct. 120 (November) (2017) 1-8.

[31] J. Zhang, Y. Wang, F. Wang and W. Tang, "Buckling of stainless steel spherical caps subjected to uniform external pressure".Ships Offshore Struct., DOI: $10.1080 / 17445302.2018 .1459358$.

[32] J. Zhang, Y. Zhang, F. Wang, Y. Zhu, W. Cui, Y. Chen, Z. Jiang, Experimental and numerical studies on the buckling of the hemispherical shells made of maraging steel subjected to extremely high external pressure, Int. J. Press. Vessel. Pip. 172 (May) (2019) 56-64.

[33] T. Kármán, H. Tsien, The buckling of spherical shells by external pressure, J. Aeronaut. Sci. 7 (1939) 43-50, https://doi.org/10.2514/8.1019.

[34] H. Tsien, Theory for the buckling of thin shells, Aeronaut. Sci. 9 (1942) 373-384, https://doi.org/10.2514/8.10911.

[35] L. Berke, R. Carlson, Experimental studies of the post buckling behaviour of complete spherical shells, Exp. Mech. 8 (1968) 548-553, https://doi.org/ 10.1007/BF02327517.

[36] W.T. Koiter, The stability of elastic equilibrium [PhD thesis] - 1945 [in Dutch], in: T.H. Delft (Ed.), Englisch Translation NASA TTF-10, 1967, pp. 1-833.

[37] W. Koiter, The nonlinear buckling problem of a complete spherical shell under uniform external pressureparts I, II, III and IV, Proc. Koninklijke Nederl. Akademie Wetenschappen B 72 (1969) 40-123.

[38] H. Wagner, E. Petersen, R. Khakimova, C. Hühne, Buckling analysis of an imperfection-insensitive hybrid composite cylinder under axial compression numerical simulation, destructive and non-destructive experimental testing, Compos. Struct. 225 (1 October) (2019) 111152.

[39] H. Wagner, C. Hühne, S. Niemann, L. Weiß, High-fidelity design methods to determine knockdown factors for the buckling load of axially loaded composite cylindrical shells, in: Shell Structures: Theory and Applications Volume 4: Proceedings of the 11th International Conference" Shell Structures: Theory and Applications, SSTA, Gdansk, Poland, 2017. October 11-13, 2017.

[40] H. Wagner, Hühne, S. Niemann, R. Khakimova, Robust design criterion for axially loaded cylindrical shells - simulation and Validation, Thin-Walled Struct. 115 (2017) 154-162.

[41] H. Wagner, C. Hühne, S. Niemann, Constant Single-Buckle Imperfection Principle to determine a lower bound for the buckling load of unstiffened composite cylinders under axial compression, Compos. Struct. 139 (2016) 120-129.

[42] H. Wagner, C. Hühne, K. Rohwer, S. Niemann, M. Wiedemann, Stimulating the realistic worst case buckling scenario of axially compressed cylindrical composite shells, Compos. Struct. 160 (2017) 1095-1104.

[43] H. Wagner, C. Hühne, S. Niemann, Robust knockdown factors for the design of axially loaded cylindrical and conical composite shells - development and Validation, Compos. Struct. 173 (2017) 281-303, https://doi.org/10.1016/j. compstruct.2017.02.031.

[44] H. Wagner, C. Hühne, S. Niemann, K. Tian, B. Wang, P. Hao, Robust knockdown factors for the design of cylindrical shells under axial compression: analysis and modeling of stiffened and unstiffened cylinders, Thin-Walled Struct. 127 (June 2018) 629-645.

[45] H. Wagner, C. Hühne, R. Khakimova, On the development of shell buckling knockdown factors for imperfection sensitive conical shells under pure bending, Thin-Walled Struct. 145 (December) (2019) 106373.

[46] J. Horak, J.G. Lord, M. Peletier, Cylinder buckling: the mountain pass as an organizing center, SIAM J. Appl. Math. 66 (5) (2006) 1793-1824.

[47] R.L. Carlson, R.L. Sendelbeck, N.J. Hoff, Experimental studies of the buckling of complete spherical shells, Exp. Mech. 7 (1967) 281-288.

[48] H. Wagner, C. Hühne, Robust knockdown factors for the design of cylindrical shells under axial compression: potentials, practical application and reliability analysis, Int. J. Mech. Sci. 135 (2018) 410-430.

[49] H. Wagner, C. Hühne, Towards robust knockdown factors for the design of conical shells under axial compression, Int. J. Mech. Sci. 146-147 (October) (2018) 60-80.

[50] J. Hutchinsona, J. Thompson, Imperfections and energy barriers in shell buckling, Int. J. Solids Struct. 148-149 (September) (2018) 157-168.

[51] "NASA, Buckling of Thin-Walled Doubly-Curved Shells, NASA Space Vehicle Design Criteria (Structures) NASA SP-8032, 1969. August 1969.

[52] J. Singer, J. Arbocz, T. Weller, Buckling experiments, experimental methods in buckling of thin-walled structures, in: Shells, Built-Up Structures, Composites and Additional Topics, vol. 2, Wiley, New York, 2002.

[53] S. Gerasimidis, E. Virot, J.W. Hutchinson, SM, Rubinstein, On establishing buckling knockdowns for imperfection-sensitive shell structures, J. Appl. Mech. 85 (9) (Jun 18, 2018), 091010 (14 pages).

[54] A. Evkin, M. Kolesnikov, O. Lykhachova, Buckling load prediction of an externally pressurized thin spherical shell with localized imperfections, Mathematirc and Mechanics of Solids (2018). https://doi.org/10.1177/1081286 517753277.

[55] A. Evkin, O. Lykhachova, Design buckling pressure for thin spherical shells: development and validation, Int. J. Solids Struct. 156-157 (January) (2019) $61-72$.
[56] A.Y. Evkin, O.V. Lykhachova, Energy barrier as a criterion for stability estimation of spherical shell under uniform external pressure, Int. J. Solids Struct. 118-119 (July) (2017) 14-23.

[57] A. Evkin, Composite Spherical Shells at Large Deflections. Asymptotic Analysis and Applications, Composite Structures, 2020 (accepted manuscript).

[58] A. Evkin, Dynamic energy barrier estimation for spherical shells under external pressure, Int. J. Mech. Sci. 160 (September) (2019) 51-58.

[59] Dassault Systems, ABAQUS 6.13-Software Package, 2013.

[60] A. Lee, F. López Jiménez, J. Marthelot, J. Hutchinson, P. Reis, The geometric role of precisely engineered imperfections on the critical buckling load of spherical elastic shells, ASME. J. Appl. Mech. 83 (11) (2016), https://doi.org/10.1115/ 1.4034431, 111005-111005-11.

[61] P. Gonceives and J. Croll, "Axisymmetric buckling of pressure-loaded spherical caps," J. Struct. Eng. 118(4), 1992.

[62] J. Croll, Towards a rationally based elastic-plastic shell buckling design, ThinWalled Struct. 23 (1995) 67-84.

[63] E. Sosa, L. Godoy, J. Croll, Computation of lower-bound elastic buckling loads using general-purpose finite element codes, Comput. Struct. 84 (29-30) (November 2006) 1934-1945.

[64] J. Croll, Towards simple estimates of shell buckling loads, Stahlbau 1 \& 2 (1975).

[65] H. Wagner, C. Hühne, S. Niemann, Robust knockdown factors for the design of spherical shells under external pressure: development and validation, Int. J. Mech. Sci. 141 (2018) 58-77.

[66] H. Wagner, Robust Design of Buckling Critical Thin-Walled Shell Structures, PhD Thesis, Technical University Carolo-Wilhelmina, Braunschweig, 2018.

[67] H. Wagner, E. Sosa, C. Hühne, T. Ludwig, J. Croll, Robust design OF imperfection sensitive thin-walled shells under axial compression, bending or external pressure, Int. J. Mech. Sci. 156 (2019) 205-220.

[68] H. Wagner, C. Hühne, J. Zhang, W. Tang, R. Khakimova, Geometric imperfection and lower-bound analysis of spherical shells under external pressure, Thin-Walled Struct. 143 (October) (2019) 106195.

[69] C. Bach, Die widerstandfähigkeit kugelförmiger wandungen gegenüber äusserem druck, Zeitschrift des Vereins deutscher Ingenieure 46 (1902) 333-341.

[70] A. Kaplan, Y. Fung, A non-linear theory of bending and buckling of thin elastic shallow spherical shells, Nat. Advisory Comm. Aeron. (1954). TN-3212.

[71] R.H. Homewood, A.A. Brine, A.E. Johnson, Experimental investigation o buckling instability of monocoque shells, Exp. Mech. 18 (1961) 88-98.

[72] R. Belinfante, Buckling of Spherical Caps under Uniform External Pressure, 1962. Douglas Aicraft company report No. SM-38938.

[73] L. Seaman, The Nature of Buckling in Thin Spherical Shells, Doctoral thesis, Watertown arsenal laboratories, 1962, https://apps.dtic.mil/dtic/tr/fulltext /u2/610809.pdf.

[74] C.W. Radtke, Buckling of Hemispherical Shells under External Pressures, Douglas Aircraft Company, 1962. Missile Division Rept. SM-3815.

[75] M. Krenzke, T. Kiernan, Tests of stiffened and unstiffened machined spherical shells under external hydrostatic pressure, in: Tests of Stiffened and Unstiffened Machined Spherical Shells under External Hydrostatic Pressure, 1963, p. 1741. David Taylor Model Basin Rept.

[76] R.R. Parmerter, The Buckling of Clamped Shallow Spherical Shells under Uniform Pressure, California Institute of Technology, 1963. Tech. Rept. AFOSR 5362.

[77] W.A. Litle, Reliability of Shell Buckling Predictions Based on Experimental Analysis of Plastic Models, Sc.D. Thesis, Massachusetts Institute of Technology, 1963.

[78] L. Wang, Discrepancy of experimental buckling pressures of spherical shells, AIAA J. 5 (1967) 357-359.

[79] R. Evan-Iwanowski, D.H. Tierney, T. Loo, Local instability of shells, in: 8th Midwestern Conference on Mechanics, vol. 1, Pergamon Press Ltd., Oxford, 1967, pp. 221-251.

[80] S. Tilman, On the buckling behavior of shallow spherical caps under uniform pressure load, Int. J. Solids Struct. 6 (1970) 37-52.

[81] M. Sunakawa, I. Kazuo, A High Precision Experiment on the Buckling of Spherical Caps Subjected to External Pressure, Institute of Space and Aeronautical Science, Universitiy of Tokyo, March 1974.

[82] S. Yamada, Theroy and Application of Shell Buckling Mechanics, Techn. Report, Department of Architecture and Civil Engineering, Toyohasi University of Technology, 1983.

[83] B. Budiansky, Buckling of clamped shallow spherical shells, in: Proc. Symp. Theory of Thin Elastic Shells, North-Holland Publ., Amsterdam, Delft, 1959.

[84] B.B. Pan, W. Cui, Y. Shen, Experimental verification of the new ultimate strength equation of spherical pressure hulls, Mar. Struct. 29 (1) (2012) 169-176.

[85] S. Kolodziej, J. Marcinowski, Experimental and numerical analyses of the buckling of steel, pressurized, spherical shells, Adv. Struct. Eng. (2018) 1-18, https://doi.org/10.1177/1369433218774371.

[86] Y. Wang, W. Tang, J. Zhang, S.C.Y. Zhang, Buckling of imperfect spherical caps with fixed boundary under uniform external pressure, Mar. Struct. 65 (2019) $1-11$.

[87] J. Zhang, Y. Wang, W. Tang, Y. Zhu, X. Zhao, Buckling of externally pressurised spherical caps with wall-thickness reduction, Thin-Walled Struct. 136 (2019) 129-137.

[88] Y. Zhu, Y. Zhang, X. Zhao, J. Zhang, X. Xu, Elastic-plastic buckling of externally pressurised hemispherical heads, Ships Offshore Struct. 14 (8) (2019) 829-838, https://doi.org/10.1080/17445302.2018.1564541.

[89] J. Zhang, C. Huang, H. Wagner, W. Cui, W. Tang, Experiments on dented hemispheres under external hydrostatic pressure, Mar. Struct. (2020) (under review). 
[90] J.W. Hutchinson, Buckling of spherical shells revisited, in: Proceedings of the Royal Soc. A 472, 2016, p. 20160577.

[91] PD 5500, Specification for Unfired Fusion Welded Pressure Vessels, 2018.

[92] P. Błażejewski, J. Marcinowski, M. Rotter, Buckling of externally pressurised spherical shells: experimental results compared with recent design recommendations, ce/papers: Special Issue: Eurosteel 1 (2-3) (2017) 1010-1018, 2017.

[93] H. Öry, H. Reimerdes, T. Schmid, G. Garcia, Imperfection sensitivity of an orthotropic spherical shell under external pressure, Int. J. Non-Linear Mech. 37 (4-5) (June 2002) 669-686.

[94] ECSS Buckling Handbook, 2010. ECSS-E-HB-32-24A, http://www.ecss.nl/wp-con tent/uploads/standards/ecss-h/ECSS-HB-32-24A24March2010.pdf.

[95] J. Wang, Z. Li, W. Yu, Structural similitude for the geometric nonlinear buckling of stiffened orthotropic shallow spherical shells by energy approach, Thin-Walled Struct. 138 (2019) 430-457.

[96] J.P. Peterson, P. Seide, V.I. Weingarten, Buckling of Thin-Walled Circular Cylinders - NASA SP-8007, Technical Report, 1 Aug 1968.
[97] H. Wagner, C. Hühne, I. Elishakoff, Probabilistic and deterministic lower-bound design benchmarks for cylindrical shells under axial compression, Thin-Walled Struct. 146 (January) (2020) 106451.

[98] J. Blachut, Buckling of near- perfect steel torispherical and hemispherical shells subjected to external pressure, AIAA J. 28 (1990) 1971-1975.

[99] K. Li, J. Zheng, S. Liu, H. Ge, G. Sun, Z. Zhang, et al., Buckling behavior of largescale thin-walled ellipsoidal head under internal pressure, Thin-Walled Struct. 141 (August) (2019) 260-274.

[100] H. Wagner, H. Köke, S. Dähne, S. Niemann, C. Hühne, R. Khakimova, Decision tree-based machine learning to optimize the laminate stacking of composite cylinders for maximum buckling load and minimum imperfection sensitivity, Compos. Struct. 220 (15 July 2019) 45-63.

[101] B. Wang, M. Xiangtao, P. Hao, Y. Sun, K. Tian, L. Gang, Z. Ke, J. Liangliang, G. Jie, Improved knockdown factors for composite cylindrical shells with delamination and geometric imperfections, Compos. B Eng. 163 (15 April 2019) 314-323. 